\title{
Depth-resolved cathodoluminescence spectroscopy of silicon supersaturated with sulfur
}

\section{Citation}

Fabbri, Filippo, Matthew J. Smith, Daniel Recht, Michael J. Aziz, Silvija Gradec\#ak, and Giancarlo Salviati. 2013. "Depth-Resolved Cathodoluminescence Spectroscopy of Silicon Supersaturated with Sulfur." Appl. Phys. Lett. 102 (3): 031909. doi:10.1063/1.4788743.

\section{Published Version}

doi:10.1063/1.4788743

\section{Permanent link}

http://nrs.harvard.edu/urn-3:HUL.InstRepos:14549989

\section{Terms of Use}

This article was downloaded from Harvard University's DASH repository, and is made available under the terms and conditions applicable to Other Posted Material, as set forth at http:// nrs.harvard.edu/urn-3:HUL.InstRepos:dash.current.terms-of-use\#LAA

\section{Share Your Story}

The Harvard community has made this article openly available.

Please share how this access benefits you. Submit a story.

\section{Accessibility}




\title{
Depth-resolved cathodoluminescence spectroscopy of silicon supersaturated with sulfur
}

\author{
Filippo Fabbri, ${ }^{1,2, a)}$ Matthew J. Smith, ${ }^{2, a)}$ Daniel Recht, ${ }^{3}$ Michael J. Aziz, ${ }^{3}$ \\ Silvija Gradečak, ${ }^{2, b)}$ and Giancarlo Salviati $\left.{ }^{1, b}\right)$ \\ ${ }^{1}$ IMEM-CNR Institute, viale Usberti 37/A, Parma, Italy \\ ${ }^{2}$ Department of Materials Science and Engineering, Massachusetts Institute of Technology, Cambridge, \\ Massachusetts 02139, USA \\ ${ }^{3}$ Harvard School of Engineering and Applied Sciences, Cambridge, Massachusetts 02138, USA
}

(Received 5 October 2012; accepted 4 January 2013; published online 24 January 2013)

\begin{abstract}
We investigate the luminescence of $\mathrm{Si}$ supersaturated with $\mathrm{S}$ ( $\mathrm{Si}: \mathrm{S}$ ) using depth-resolved cathodoluminescence spectroscopy and secondary ion mass spectroscopy as the $\mathrm{S}$ concentration is varied over 2 orders of magnitude $\left(10^{18}-10^{20} \mathrm{~cm}^{-3}\right)$. In single-crystalline supersaturated Si:S, we identify strong luminescence from intra-gap states related to Si self-interstitials and a S-related luminescence at $0.85 \mathrm{eV}$, both of which show a strong dependence on $\mathrm{S}$ concentration in the supersaturated regime. Sufficiently high $\mathrm{S}$ concentrations in $\mathrm{Si}\left(>10^{20} \mathrm{~cm}^{-3}\right)$ result in complete luminescence quenching, which we propose is a consequence of the overlapping of the defect band and conduction band. (C) 2013 American Institute of Physics. [http://dx.doi.org/10.1063/1.4788743]
\end{abstract}

The ability to tailor the optoelectronic properties of $\mathrm{Si}$ by doping with $\mathrm{S}$ has been an active area of research for several decades. At equilibrium concentrations ${ }^{1}\left(10^{16}\right.$ $\left.-10^{17} \mathrm{~cm}^{-3}\right)$, Si doped with $\mathrm{S}(\mathrm{Si}: \mathrm{S})$ offers a potential route to high-efficiency Si-based light emission ${ }^{2,3}$ due to metastable, optically active S-complexes. ${ }^{4-6}$ In a different regime of doping, Si doped with $\mathrm{S}$ to beyond-equilibrium concentrations $\left(10^{18}-10^{20} \mathrm{~cm}^{-3}\right)$ was found to exhibit enhanced sub-band gap absorption ${ }^{7,8}$ and has been used to fabricate photodiodes with increased gain and extended optoelectronic response $^{9}$ down to energies less than $0.5 \mathrm{eV} .^{10}$ The changes in the optoelectronic properties of $\mathrm{Si}$ induced by supersaturated concentrations of chalcogens $(S, S e, T e)$ exhibit a strong concentration dependence, which has been related both theoretically ${ }^{11}$ and experimentally ${ }^{12,13}$ to impurityinduced changes to the band structure. Although S in Si at dilute concentrations affects luminescence and, at supersaturated concentrations, drastically affects the optoelectronic properties, the effects of supersaturated concentrations of $S$ on the luminescence of Si remains unexplored.

The controlled synthesis of single-crystalline Si doped with $\mathrm{S}$ above the equilibrium solubility limit can be achieved using ion implantation followed by pulsed laser melting (PLM). ${ }^{14-16}$ One important consequence of this technique is that the resulting dopant profile exhibits a surface layer that is uniformly doped and, beneath that, a concentration tail that decays over hundreds of nanometers. As a result, the optoelectronic properties of supersaturated Si:S exhibit a strong depth-dependence. ${ }^{14}$ The inhomogeneous doping makes it challenging to study the relationship between band structure and $\mathrm{S}$ concentration through bulk characterization; so far, iterative characterization and etching have been needed to characterize how material properties change with depth and thus with $\mathrm{S}$ concentration. ${ }^{14,17}$

\footnotetext{
${ }^{\text {a) }}$ F. Fabbri and M. J. Smith contributed equally to this work.

${ }^{b)}$ Authors to whom correspondence should be addressed. Electronic addresses: giancarlo.salviati@cnr.it and gradecak@mit.edu.
}

In this study, we combine depth-resolved cathodoluminescence (CL) spectroscopy ${ }^{18-20}$ and secondary ion mass spectroscopy (SIMS) to investigate the relationship between luminescence and dopant concentration in Si doped with $\mathrm{S}$ to beyond-equilibrium concentrations. A sulfur-related subband gap luminescence is reported at $0.85 \mathrm{eV}$, distinct from the S-related luminescent centers previously observed at dilute $\mathrm{S}$ concentrations. We identify a S-concentration threshold above which all luminescence is quenched, and correlation with other bulk characterization techniques suggests that the luminescent quenching may be related to $\mathrm{S}$ impurity-band overlap with the conduction band.

$\mathrm{S}$-supersaturated $\mathrm{Si}$ was prepared by ion implantation of (100) Si (p-type, 10-20 $\Omega$-cm, Czochralski-grown) with ${ }^{32} \mathrm{~S}^{+}$ ions at $95 \mathrm{keV}$ and at $7^{\circ}$ off-normal to prevent channeling, followed by PLM. ${ }^{12}$ To study concentration dependence, four different wafers were implanted with $\mathrm{S}$ doses of $1 \times 10^{16} \mathrm{~cm}^{-2}$, $3 \times 10^{15} \mathrm{~cm}^{-2}, 1 \times 10^{15} \mathrm{~cm}^{-2}$, and $3 \times 10^{14} \mathrm{~cm}^{-2}$ prior to $\mathrm{PLM}$ with $\mathrm{XeCl}$ irradiation $(308 \mathrm{~nm}, 25 \mathrm{~ns}$ at full width at half maximum, $50 \mathrm{~ns}$ total duration). Each sample received four consecutive $\mathrm{XeCl}$ pulses at fluences of 1.7, 1.7, 1.7, and 1.8 $\mathrm{Jcm}^{-2}$. To ensure complete amorphization prior to PLM, the $3 \times 10^{14} \mathrm{~cm}^{-2}$ and $1 \times 10^{15} \mathrm{~cm}^{-2}$ S-implanted samples were pre-amorphized with a Si implantation of $3 \times 10^{15} \mathrm{~cm}^{-2}$ before $\mathrm{S}$ implantation. To separate the effects of ion implantation and pulsed laser melting from S-related effects, we also implanted a Si wafer with $1 \times 10^{16} \mathrm{~cm}^{-2}$ Si prior to PLM. All samples presented in this work were irradiated under identical conditions described above and, in the following, will be referred to solely by their implantation dose. The resulting $\mathrm{S}$ concentration profiles were determined by SIMS for the samples implanted with $\mathrm{S}$ at doses of $1 \times 10^{16} \mathrm{~cm}^{-2}$ and $3 \times 10^{15} \mathrm{~cm}^{-2}$. The post-PLM concentration profiles for the $1 \times 10^{15} \mathrm{~cm}^{-2}$ and $3 \times 10^{14} \mathrm{~cm}^{-2}$ dose samples were approximated by scaling down the SIMS $\mathrm{S}$ profiles of the $1 \times 10^{16} \mathrm{~cm}^{-2}$ and $3 \times 10^{15} \mathrm{~cm}^{-2}$ dose samples. ${ }^{12}$ All SIMS spectra are shown in Figure 1.

Depth-resolved CL was carried out with a commercial Gatan monoCL system on an S360 Cambridge Scanning 


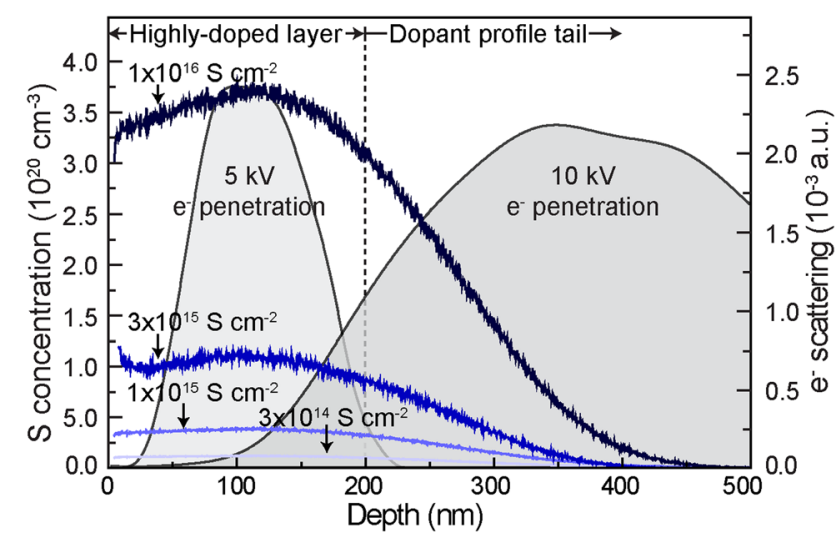

FIG. 1. Sulfur profile following ion implantation and pulsed laser melting determined by SIMS $\left(1 \times 10^{16} \mathrm{~S} \mathrm{~cm}^{-2}, 3 \times 10^{15} \mathrm{~cm}^{-2}\right)$ and extrapolated to lower $\mathrm{S}$ doses $\left(1 \times 10^{15} \mathrm{~cm}^{-2}\right.$ and $\left.3 \times 10^{14} \mathrm{~cm}^{-2}\right)$. The equilibrium concentration of $\mathrm{S}\left(1 \times 10^{16}-1 \times 10^{17} \mathrm{~cm}^{-3}\right)$ is not visible on this scale. The interaction volume of depth-resolved CL at $5 \mathrm{kV}$ and $10 \mathrm{kV}$ is overlaid (right axis), showing the distribution of electron scattering events through which the electron beam loses $60 \%$ of its starting energy in the Monte Carlo simulations.

Electron Microscope. The CL system is equipped with a Ge photodiode to detect near infrared emission, sensitive from 600 to $1700 \mathrm{~nm}(2.0 \mathrm{eV}-0.7 \mathrm{eV})$. All the CL experiments were performed at liquid nitrogen temperature $(77 \mathrm{~K})$ with a dwell time per pixel of $67 \mathrm{~ns}$ and an acquisition time of $3 \mathrm{~ms}$ per wavelength step $(1 \mathrm{~nm})$. In the depth-dependent CL analyses, we used accelerating voltages of both 5 and $10 \mathrm{kV}$, keeping the total power density constant at $2 \times 10^{6} \mathrm{~W} / \mathrm{cm}^{3}$. The total power density was calculated as the product of the accelerating voltage and the beam current, divided by the volume probed. The probed area was $120 \times 80 \mu \mathrm{m}^{2}$ and the probed depth at $5 \mathrm{kV}$ and $10 \mathrm{kV}$ was estimated using Monte Carlo simulation of the electron trajectories. ${ }^{21}$ To illustrate the depth-sensitivity of the electron-material interactions, we plot in Figure 1 the distribution of electron scattering events through which the electron beam loses $60 \%$ of its starting energy in the Monte Carlo simulations. Though the interaction volume is larger and has a diffuse boundary, this plot illustrates the regions of highest-density energy deposition and signal generation. The comparable height of the $5 \mathrm{kV}$ and $10 \mathrm{kV}$ peaks is a result of the experimental normalization of the total power density, described above.

Investigating $\mathrm{CL}$ at both $5 \mathrm{kV}$ and $10 \mathrm{kV}$ allows for the probing of distinct regions of the Si:S supersaturated layer. Figure 1 shows the SIMS doping profile that forms following PLM of $\mathrm{Si}$ ion-implanted with $\mathrm{S}$ across a range of $\mathrm{S}$ doses $\left(3 \times 10^{14} \mathrm{~cm}^{-2}-1 \times 10^{16} \mathrm{~cm}^{-2}\right)$. Both $1 \times 10^{16} \mathrm{~cm}^{-2}$ and $3 \times 10^{15} \mathrm{~cm}^{-2}$ samples exhibit an approximately $200 \mathrm{~nm}$ thick plateau at the surface, indicating that a relatively uniform concentration of $\mathrm{S}$ is formed at the surface. Beneath this layer, a tail region is observed in which the $\mathrm{S}$ concentration gradually drops off as it approaches the melt depth approximately $400 \mathrm{~nm}$ below the surface. Comparison of the distribution of electron scattering events during CL with the S profile (Figure 1) illustrates the ability to probe primarily the high-concentration plateau and the dopant profile tail separately by switching between $5 \mathrm{kV}$ and $10 \mathrm{kV}$ accelerating voltages, respectively.

An important consideration when conducting depthresolved $\mathrm{CL}$ of $\mathrm{Si}: \mathrm{S}$ is the influence of the changing $\mathrm{S}$ con- centration on self-absorption, as the sub-band gap absorptance is strongly affected by the degree of $\mathrm{S}$ supersaturation in $\mathrm{Si}^{16}$ The upper-limit of these effects can be calculated using the reported concentration-dependent values of $\alpha d$ of $\mathrm{Si}: \mathrm{S},{ }^{22}$ where $\alpha$ is the absorption coefficient and $d$ is the effective thickness. We use the Beer-Lambert law to estimate the changes in self-absorption when increasing from $\mathrm{S}$ doses of $3 \times 10^{14} \mathrm{~cm}^{-2}$ to $1 \times 10^{16} \mathrm{~cm}^{-2}$ and find that the maximum expected decrease in luminescent intensity due to the increased $\mathrm{S}$ concentration is $34 \%$ in this doping regime. The effects of self-absorption may complicate the quantification of the observed trends in luminescence, but we note that in the following investigations, all trends of modulated luminescence with changes in the doping dose (which could include self-absorption effects) significantly exceed $34 \%$. Therefore, qualitative discussions of the observed trends in luminescence are possible in our case.

We first isolate luminescence due to PLM-induced point defects by investigating the CL of Si samples implanted with $1 \times 10^{16} \mathrm{~cm}^{-2} \mathrm{Si}$ compared with that of an untreated $\mathrm{Si}$ wafer. At $5 \mathrm{kV}$ (Figure 2(a)) and $10 \mathrm{kV}$ (Figure 2(b)), the pristine $\mathrm{Si}$ wafer shows only a peak centered at $1.1 \mathrm{eV}$ corresponding to the band-to-band transition in Si (BB-line). ${ }^{23,24}$ At both $5 \mathrm{kV}$ and $10 \mathrm{kV}$, the $1 \times 10^{16} \mathrm{~cm}^{-2}$ Si-dose sample exhibits decreased intensity of the BB-line, and a broad emission at $0.99 \mathrm{eV}$ simultaneously appears. The decrease in intensity of the BB-line is attributed to increased nonradiative recombination due to PLM-induced point defects. The luminescence at $0.99 \mathrm{eV}$ is identical to the band observed by Pankove and $\mathrm{Wu}^{25}$ following ion implantation of $\mathrm{Si}$ with $\mathrm{Si}$ and annealing at $300{ }^{\circ} \mathrm{C}$ in $\mathrm{H}_{2}$. This luminescent feature is attributed to phonon modes of the X-center (also known as the $\mathrm{I}_{3}$ band $)^{26}$ that has been proposed to arise from a Si selfinterstitial complex. ${ }^{27}$ Increasing the accelerating voltage from $5 \mathrm{kV}$ to $10 \mathrm{kV}$ results in a higher relative intensity of the BB-line compared to the $0.99 \mathrm{eV}$ band, which can be attributed to the increased volume of unaffected $\mathrm{Si}$ that is probed using $10 \mathrm{kV}$ accelerating voltage (Figure 1).

Next, we elucidate the effects of S-supersaturation by comparing $\mathrm{Si}$ implanted with $\mathrm{Si}$ to $\mathrm{Si}$ implanted with $\mathrm{S}$ at an identical dose $\left(1 \times 10^{16} \mathrm{~cm}^{-2}\right)$. The CL spectra of the $1 \times 10^{16} \mathrm{~cm}^{-2} \mathrm{~S}$-supersaturated sample taken at $5 \mathrm{kV}$ (Figure 2(a)), which probes the most highly doped region (Figure 1), exhibit significantly reduced overall intensity without clearly resolvable luminescent bands. Increasing the accelerating voltage to $10 \mathrm{kV}$, thus probing the tail of the doped profile, results in the appearance of the BB-line at $1.1 \mathrm{eV}$ and a $\mathrm{CL}$ band centered around $0.85 \mathrm{eV}$. The luminescence at $0.85 \mathrm{eV}$ does not appear in either the $5 \mathrm{kV}$ or $10 \mathrm{kV}$ spectra from the $\mathrm{Si}$-implanted sample and is therefore related to the presence of S. Here, we note that the S-related luminescence at $0.85 \mathrm{eV}$ observed in our supersaturated samples is different from the metastable luminescence centers at $0.82 \mathrm{eV}(1.5 \mu \mathrm{m})$ and $0.94 \mathrm{eV}(1.32 \mu \mathrm{m})$ that have been observed in Si containing equilibrium concentrations of $\mathrm{S}$ (concentrations 1-3 orders of magnitude lower than investigated here). ${ }^{2,4-6}$

To better understand the effect of S-supersaturation on the implantation-related band at $0.99 \mathrm{eV}$ and the S-related band around $0.85 \mathrm{eV}$, the implanted $\mathrm{S}$ dose was decreased from $1 \times 10^{16} \mathrm{~cm}^{-2}$ to as low as $3 \times 10^{14} \mathrm{~cm}^{-2}$ and the 


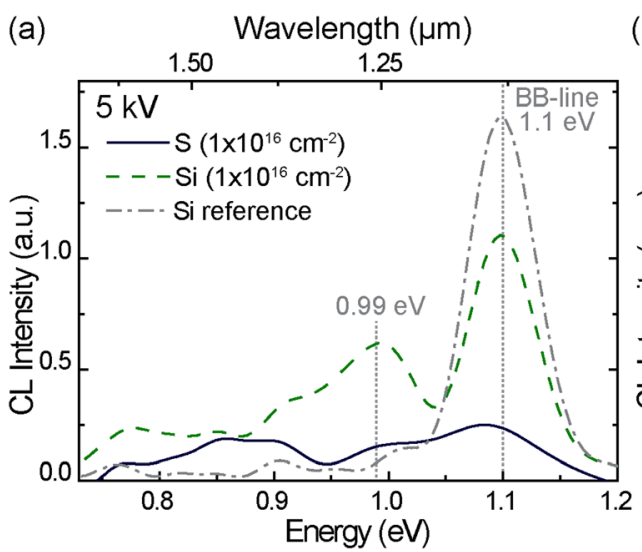

FIG. 2. CL spectra obtained at (a) $5 \mathrm{kV}$ and (b) $10 \mathrm{kV}$ at $77 \mathrm{~K}$ of $\mathrm{Si}$ implanted with S (blue, solid) and $\mathrm{Si}$ (green, dashed) with an equivalent dose of $1 \times 10^{16} \mathrm{~cm}^{-2}$ followed by PLM. Implantation and PLM with only Si causes a decrease in the BBline and the appearance of a broad emission at $0.99 \mathrm{eV}$. Implantation and PLM with $\mathrm{S}$ drastically reduces luminescence in the highly doped surface layer $(5 \mathrm{kV})$ and probing deeper $(10 \mathrm{kV})$ reveals a sulfur-related luminescence at $0.85 \mathrm{eV}$. The CL spectrum of an untreated Si wafer is included for reference. resulting luminescence was measured at $5 \mathrm{kV}$ (Figure 3(a)) and $10 \mathrm{kV}$ (Figure $3(\mathrm{~b})$ ). When the $\mathrm{S}$ dose is decreased to $3 \times 10^{15} \mathrm{~cm}^{-2}$, the band at $0.99 \mathrm{eV}$ appears, which has been attributed to $\mathrm{Si}$ self-interstitials. ${ }^{25-27}$ Recall this band was observed in the $1 \times 10^{16} \mathrm{~cm}^{-2}$ Si-implanted sample but absent in the S-implanted sample of the same dose. Furthermore, we observe a strong increase in the intensity of the $0.99 \mathrm{eV}$ band with decreasing $\mathrm{S}$ dose. Lower doses of $\mathrm{S}$ than used in this study $\left(1 \times 10^{14} \mathrm{~S} \mathrm{~cm}^{-2}\right)$, followed by PLM, have been used to fabricate light emitting diodes based on zerophonon luminescence from the $\mathrm{W}$-line $(1.018 \mathrm{eV}),{ }^{28}$ which is also attributed to Si self-interstitials caused by the implantation process, ${ }^{27}$ but the dependence of this luminescence on $\mathrm{S}$ concentration was not investigated. It has been previously reported that the intensity of the $0.99 \mathrm{eV}$ band increases upon annealing of ion-implanted $\mathrm{Si}$ in $\mathrm{H}_{2}$ ambient ${ }^{26}$ and this behavior was attributed to the ability of $\mathrm{H}$ to passivate competing nonradiative recombination pathways. $S$ impurities have been shown to provide both radiative and non-radiative recombination pathways, and thus we attribute the decreasing $0.99 \mathrm{eV}$ luminescence with increasing $\mathrm{S}$ concentration to the associated non-radiative recombination pathways. ${ }^{2,4}$

The general trends in the luminescence spectra of $\mathrm{Si}: \mathrm{S}$ samples at $10 \mathrm{kV}$ (BB-line, $0.99 \mathrm{eV}$ band, and $0.85 \mathrm{eV}$ band) are similar to those collected at $5 \mathrm{kV}$. The band centered at $0.85 \mathrm{eV}$ appears in the $3 \times 10^{15} \mathrm{~cm}^{-2} \mathrm{~S}$-dose sample at $5 \mathrm{kV}$, increases in intensity as the dose is decreased further to $1 \times 10^{15} \mathrm{~cm}^{-2}$, and remains constant as the $\mathrm{S}$ dose is further decreased to $3 \times 10^{14} \mathrm{~cm}^{-2}$, which indicates that this luminescence band is relatively insensitive to $\mathrm{S}$ concentration in this re- gime. This is in stark contrast to the concentration dependence of the $0.99 \mathrm{eV}$ band, which monotonically decreases with increasing $\mathrm{S}$ concentration.

Using ion implantation and PLM to synthesize Si:S, we have identified a S-related luminescence at $0.85 \mathrm{eV}$. There are two known $\mathrm{S}$ states with energy levels that align well with the $0.85 \mathrm{eV}$ band: a neutral $\mathrm{S}$ substitutional atom ${ }^{29}$ or a charged $\mathrm{S}$ dimer, ${ }^{30}$ with energies $320 \mathrm{meV}$ and $371 \mathrm{meV}$ below the conduction band, respectively. However, S-related luminescence at these energies has not been previously reported. One possibility is that increased impurity-impurity interactions at supersaturated concentrations lead to changes in the luminescent behavior of $\mathrm{S}$ impurities, but we would expect such a phenomenon to show strong concentration dependence. Alternatively, it is possible that the band at $0.85 \mathrm{eV}$ is related to a metastable $\mathrm{S}$ complex arising from the PLM process. The melting and ultrafast resolidification during PLM represents a unique processing regime that, as evidenced by the supersaturated concentrations of $\mathrm{S}$ achieved, produces metastable impurity distributions. Furthermore, metastable luminescent S-complexes have been previously observed, though at different energy levels: S complexes observed at dilute S-concentrations at $0.82 \mathrm{eV}$ and $0.94 \mathrm{eV}$ form only after heating with a blow torch and quenching in ethylene glycol. ${ }^{4,5}$ Further investigations will be necessary to understand the source of the S-related luminescence at $0.85 \mathrm{eV}$.

Finally, the concentration dependence of the luminescence from supersaturated $\mathrm{Si}: \mathrm{S}$ provides evidence of the $\mathrm{S}$-induced changes in the band structure as concentrations
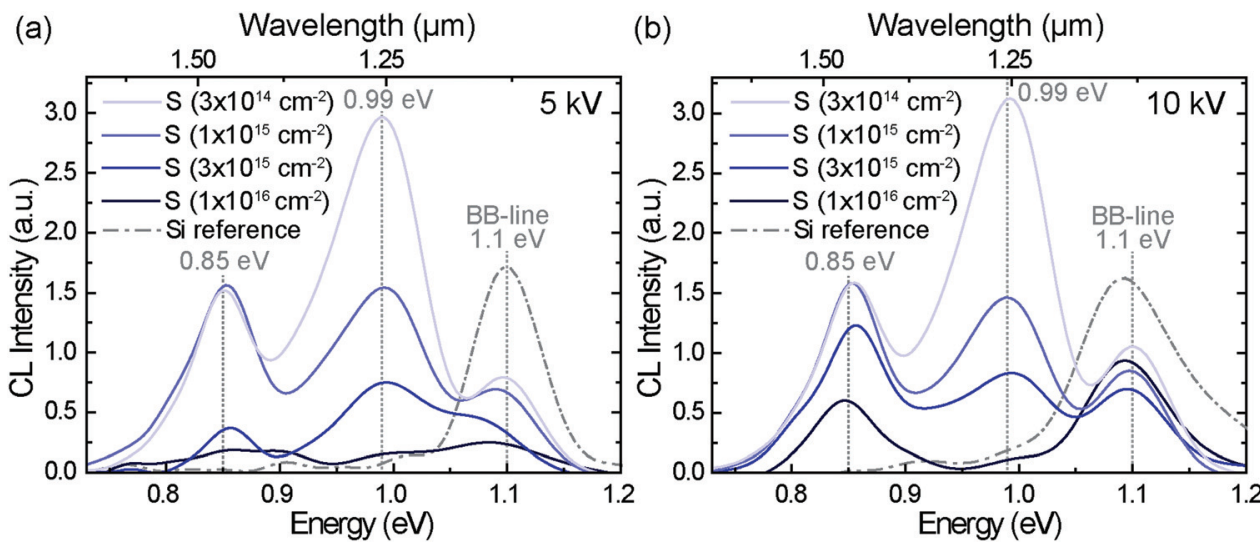

FIG. 3. The CL analysis, carried out at (a) $5 \mathrm{kV}$ and (b) $10 \mathrm{kV}$, of Si supersaturated with S, labeled by implanted dose. The intensity of both the implantation-related luminescence at $0.99 \mathrm{eV}$ and the S-related luminescence at $0.85 \mathrm{eV}$ increases with decreasing S-implantation, but at different rates. The concentration dependence of both CL bands is discussed further in the text. The CL spectrum of an untreated $\mathrm{Si}$ wafer is included for reference. 
approach 1 at. \%. In the $5 \mathrm{kV}$ spectra (Figure 3(a)), each luminescent band (BB-line, $0.99 \mathrm{eV}, 0.85 \mathrm{eV}$ ) shows a unique concentration dependence as the dose is increased from $3 \times 10^{14} \mathrm{~cm}^{-2}$ to $3 \times 10^{15} \mathrm{~cm}^{-2}$, but are suppressed when the dose is further increased to $1 \times 10^{16} \mathrm{~cm}^{-2}$. The lack of luminescence from the $1 \times 10^{16} \mathrm{~cm}^{-2} \mathrm{~S}$-implanted sample at $5 \mathrm{kV}$ suggests that a $\mathrm{S}$ concentration around $3.5 \times 10^{20} \mathrm{~cm}^{-3}(0.7$ at. \%) quenches luminescence from Si:S (Figure 1). Furthermore, the onset of quenching is visible in the $3 \times 10^{15} \mathrm{~cm}^{-2}$ spectra at $5 \mathrm{kV}$ where the intensity of the $0.85 \mathrm{eV}$ and the BBline is significantly less than the level they maintained from $3 \times 10^{14} \mathrm{~cm}^{-2}$ to $3 \times 10^{15} \mathrm{~cm}^{-2}$. Within the resolution of this characterization, we can say that the onset of quenching occurs around or just above the peak concentrations of $\mathrm{S}$ in the $3 \times 10^{15} \mathrm{~cm}^{-2}$ sample $\left(1 \times 10^{20} \mathrm{~S} \mathrm{~cm}^{-3}\right.$ or 0.2 at. $\left.\%\right)$.

Previous investigations into the optoelectronic properties of supersaturated Si:S ${ }^{12,13,16}$ indicate the emergence of an impurity band from impurity levels in the gap with increasing chalcogen concentration, ${ }^{11,31}$ leading to drastic changes to the band structure at a concentration threshold similar to where we observe luminescent quenching $\left(\geq 1 \times 10^{20} \mathrm{~cm}^{-3}\right)$. Combined computational ${ }^{11}$ and experimental investigations ${ }^{11,13}$ of the effect of increasing chalcogen concentration on the band structure suggests an insulator-metal transition due to the overlapping of the defect and conduction bands at $\mathrm{S}$ concentrations above $1 \times 10^{20} \mathrm{~cm}^{-3}$, and this model accurately predicts the observed increased sub-band gap absorptance. $^{7,11}$ The concentration thresholds at which the chalcogen-induced defect band is predicted to overlap with the conduction band ${ }^{11}\left(1 \times 10^{20} \mathrm{~cm}^{-3}\right)$ and at which a Sinduced insulator-metal transition has been observed experimentally $^{13}\left(1.8 \times 10^{20}-4.3 \times 10^{20} \mathrm{~cm}^{-3}\right)$ agree well with the onset of quenching that we observe using depth-resolved CL spectroscopy $\left(\geq 1 \times 10^{20} \mathrm{~cm}^{-3}\right)$. Thus, our investigation of the concentration-dependence of luminescence agrees with the band-overlap model, as the impurity and conduction band overlapping could feasibly result in luminescent quenching near the band edge. Finally, although the sub-band gap absorptance ${ }^{7}$ and impurity-mediated conduction ${ }^{13}$ increases with increasing $\mathrm{S}$ concentration, we have shown that S-induced changes in the band structure at concentrations above $1 \times 10^{20} \mathrm{~cm}^{-3}$ are not conducive to enhancing sub-band gap luminescence. These investigations highlight, however, the orders of magnitude of S-supersaturation $\left(10^{18}\right.$ $10^{19} \mathrm{~cm}^{-3}$ ) that could potentially allow for simultaneous subband gap absorptance, increased gain and extended response in photodiodes, and luminescence.

In summary, we have combined depth-resolved CL and SIMS to elucidate the luminescent behavior of Si:S and the effect of varying the concentration within the supersaturated regime. We find that band-to-band luminescence is reduced by the presence of $\mathrm{S}$ and further decreases with increasing $\mathrm{S}$ concentration. Luminescence at $0.99 \mathrm{eV}$, attributed to $\mathrm{Si}$ self-interstitial clusters, shows a pronounced increase in intensity with decreasing $\mathrm{S}$ concentration which we attribute to a reduction in competing non-radiative recombination pathways. We report S-related luminescence around $0.85 \mathrm{eV}$ that corresponds well with the energy levels of a substitutional S atom or a charged $\mathrm{S}$ dimer in $\mathrm{Si}$, though further studies are needed to elucidate its exact nature and its appearance only at supersaturated concentrations of $\mathrm{S}$. Above $1 \times 10^{20} \mathrm{~S}$ $\mathrm{cm}^{-3}$, we observe quenching of all luminescence, the onset of which correlates well with predicted overlapping of the defect band and conduction band. This work demonstrates the efficacy of depth-resolved CL for probing the depth dependence of luminescence in alloys fabricated using ion implantation and pulsed laser melting and reveals the concentration-dependent luminescent properties of Ssupersaturated $\mathrm{Si}$.

The authors would like to acknowledge insightful discussions with Joseph Sullivan and Dr. Christie Simmons. Research at MIT was supported by the Chesonis Family Foundation, the NSF ERC - QESST (EEC-1041895). Research at Harvard was supported by U.S. Army Research Office grant W911NF-12-1-0196. D.R. acknowledges a Department of Defense National Defense Science and Engineering Graduate Fellowship.

${ }^{1}$ R. O. Carlson, R. N. Hall, and E. M. Pell, J. Phys. Chem. Solids 8, 81 (1959).

${ }^{2}$ S. F. Galata, M. A. Lourenço, R. M. Gwilliam, and K. P. Homewod, Mater. Sci. Eng., B 124-125, 435 (2005).

${ }^{3}$ J. G. Zhang, X. X. Wang, B. W. Cheng, J. Z. Yu, Q. M. Wang, J. Hau, L. Ding, and W. K. Ge, Appl. Phys. Lett. 90, 081101 (2007).

${ }^{4}$ T. G. Brown, P. L. Bradfield, and D. G. Hall, Appl. Phys. Lett. 51, 1585 (1987).

${ }^{5}$ T. G. Brown and D. G. Hall, Appl. Phys. Lett. 49, 245 (1986).

${ }^{6}$ P. W. Mason, H. J. Sun, B. Ittermann, S. S. Ostapenko, G. D. Watkins, L. Jeyanathan, M. Singh, G. Davies, and E. C. Lightowlers, Phys. Rev. B 58, 7007 (1998).

${ }^{7}$ S. H. Pan, D. Recht, S. Charnvanichborikarn, J. S. Williams, and M. J. Aziz, Appl. Phys. Lett. 98, 121913 (2011).

${ }^{8}$ M.-J. Sher, M. T. Winkler, and E. Mazur, MRS Bull. 36, 439 (2011).

${ }^{9}$ A. J. Said, D. Recht, J. T. Sullivan, J. M. Warrender, T. Buonassisi, P. D. Persans, and M. J. Aziz, Appl. Phys. Lett. 99, 073503 (2011).

${ }^{10}$ J. E. Carey, C. H. Crouch, M. Shen, and E. Mazur, Opt. Lett. 30, 1773 (2005).

${ }^{11}$ E. Ertekin, M. T. Winkler, D. Recht, A. J. Said, M. J. Aziz, T. Buonassisi, and J. C. Grossman, Phys. Rev. Lett. 108, 026401 (2012).

${ }^{12}$ J. T. Sullivan, R. G. Wilks, M. T. Winkler, L. Weinhardt, D. Recht, A. J. Said, B. K. Newman, Y. Zhang, M. Blum, S. Krause, W. L. Yang, C. Heske, M. J. Aziz, M. Bar, and T. Buonassisi, Appl. Phys. Lett. 99, 142102 (2011).

${ }^{13}$ M. T. Winkler, D. Recht, M.-J. Sher, A. J. Said, E. Mazur, and M. J. Aziz, Phys. Rev. Lett. 106, 178701 (2011).

${ }^{14}$ B. P. Bob, A. Kohno, S. Charnvanichborikarn, J. M. Warrender, I. Umezu, M. Tabbal, J. S. Williams, and M. J. Aziz, J. Appl. Phys. 107, 123506 (2010).

${ }^{15}$ M. Tabbal, T. Kim, J. M. Warrender, M. J. Aziz, B. L. Cardozo, and R. S. Goldman, J. Vac. Sci. Technol. B 25, 1847 (2007).

${ }^{16}$ T. G. Kim, J. M. Warrender, and M. J. Aziz, Appl. Phys. Lett. 88, 241902 (2006).

${ }^{17}$ Y. Yang, J. Bao, C. Wang, and M. J. Aziz, J. Appl. Phys. 107, 123109 (2010).

${ }^{18}$ L. J. Brillson, J. Phys. D: Appl. Phys. 45, 183001 (2012).

${ }^{19}$ G. Salviati, F. Rossi, N. Armani, V. Grillo, O. Martinez, A. Vinattieri, B. Damilano, A. Matsuse, and N. Grandjean, J. Phys.: Condens. Matter 16, S1 15 (2004).

${ }^{20}$ B. G. Yacobi and D. B. Holt, Cathodoluminescence Microscopy of Inorganic Solids (Plenum, New York, N.Y., 1990).

${ }^{21}$ P. Hovington, D. Drouin, and R. Gauvin, Scanning 19, 1 (1997).

${ }^{22}$ I. Umezu, A. Kohno, J. M. Warrender, Y. Takatori, Y. Hirao, S. Nakagawa, A. Sugimura, S. Charnvanichborikarn, J. S. Williams, and M. J. Aziz, AIP Conf. Proc. 1399, 51 (2011).

${ }^{23}$ M. Kittler, T. Arguirov, A. Fischer, and W. Seifert, Opt. Mater. 27, 967 (2005).

${ }^{24}$ M. Kittler, X. Yu, T. McHedlidze, T. Arguirov, O. F. Vyvenko, W. Seifert, M. Reiche, T. Wilhelm, M. Seibt, O. Voß, A. Wolff, and W. Fritzsche, Small 3, 964 (2007).

${ }^{25}$ J. I. Pankove and C. P. Wu, Appl. Phys. Lett. 35, 937 (1979). 
${ }^{26}$ M. L. W. Thewalt, T. Steiner, and J. I. Pankove, J. Appl. Phys. 57, 498 (1985).

${ }^{27}$ A. T. Blumenau, R. Jones, S. Öberg, P. R. Briddon, and T. Frauenheim, Phys. Rev. Lett. 87, 187404 (2001).

${ }^{28}$ J. Bao, M. Tabbal, T. Kim, S. Charnvanichborikarn, J. S. Williams, M. J. Aziz, and F. Capasso, Opt. Express 15, 6727 (2007).
${ }^{29}$ H. G. Grimmeiss, E. Janzen, and B. Skarstam, J. Appl. Phys. 51, 4212 (1980).

${ }^{30}$ E. Janzén, R. Stedman, G. Grossmann, and H. G. Grimmeiss, Phys. Rev. B 29, 1907 (1984).

${ }^{31}$ K. Sánchez, I. Aguilera, P. Palacios, and P. Wahnón, Phys. Rev. B 82, 165201 (2010). 